\title{
The Evolution Process on Information Technology Outsourcing Relationship
}

\author{
Weihua Duan ${ }^{1}$ \\ ${ }^{1}$ School of Business Administration, Jilin University of Finance and Economics, Changchun 130117, China \\ Corresponding author: duanweihua@jlufe.edu.cn
}

\begin{abstract}
Information technology outsourcing relationship is one of the key issues to IT outsourcing success. To explore how to manage and promote IT outsourcing relationship, it is necessary to understand its evolution process. Firstly, the types of IT outsourcing based on relationship quality and IT outsourcing project level will be analyzed; Secondly, two evolution process models of IT outsourcing relationship are proposed based on relationship quality and IT outsourcing project level, and the IT outsourcing relationship evolution process is indicated; Finally, an IT outsourcing relationship evolution process model is developed, and the development process of IT outsourcing relationship from low to high under the internal and external power is explained.
\end{abstract}

\section{Introduction}

In [1], Qi had pointed out that information technology (IT) outsourcing has become the most important way of enterprise information construction. Many scholars form domestic and foreign have carried on the research on the IT outsourcing, and have achieved many research results, but the research on the IT outsourcing relationship is relatively little [2], and the related research is not systematic and deep. Goles research shows that there is an important link between the successes of IT outsourcing and IT outsourcing relationship [3-6]. Understanding the evolution process of IT outsourcing relationship can effectively guide enterprises to manage the IT outsourcing relationship, so as to improve the success rate of IT outsourcing. This paper analyses the evolution process of IT outsourcing relationship from the following two dimensions: Relationship quality between IT outsourcing subject and its objective IT outsourcing project.

\section{Type partition of IT outsourcing relationship}

IT outsourcing relationship is a dynamic cooperation process, which is built on the customer outsourcings its IT project to vender by contract. IT outsourcing relationship emphasizes three points: (1) two partners of the relationship are vender and customer; (2) IT outsourcing project is the foundation of the relationship; (3) relationship is a dynamic cooperation process. Thus, the subject and object of the outsourcing relationship are the essential elements of the relationship, that is, the two partners and the outsourcing project are necessary elements for the relationship. This paper bases on the relationship quality of partners and the level of IT outsourcing project to divide the IT outsourcing relationship.

\subsection{Relationship quality between IT outsourcing partners}


Relationship quality is an important concept in relationship marketing theory. Relationship quality is the degree of trust and commitment between customers and service providers [7], which is partners' common recognition to the degree of relationship satisfaction [8]. In the field of IT outsourcing, the relationship quality is considered as "the degree of the expected results of the relationship between vender and customer" [9], which is an important indicator to measure the relationship between IT outsourcing relationship.

In this paper, according to the relationship quality, IT outsourcing is divided into market relationship, cooperative relationship and partnership. The characteristics of relationships are shown in Table 1.

Table 1. Contrast of market relationship and partnership.

\begin{tabular}{|c|c|c|}
\hline Characteristics & Partnership & $\begin{array}{c}\text { Market Relation- } \\
\text { ship }\end{array}$ \\
\hline communication & $\begin{array}{c}\text { Important, } \\
\text { Frequent }\end{array}$ & $\begin{array}{c}\text { Unimportant, Not } \\
\text { frequent }\end{array}$ \\
\hline Trust & High & Low \\
\hline Cooperation & High & Low \\
\hline Uncertainty & High & Short \\
\hline Relationship & Long & Price \\
\hline $\begin{array}{c}\text { Control Mode } \\
\text { and Price }\end{array}$ & Trust, Right & Low \\
\hline Conversion cost & High & $\begin{array}{c}\text { Clearly defined in } \\
\text { contract }\end{array}$ \\
\hline $\begin{array}{c}\text { Interests and } \\
\text { Risk }\end{array}$ & Sharing \\
\hline
\end{tabular}

\subsection{The impact of IT outsourcing project on the customer's strategic}

IT outsourcing project is a bridge between the two sides of the IT outsourcing. The impact of IT outsourcing project on the customer's strategic directly affect the outsourcing relationship[10-11].IT outsourcing project is different level [12-14], the higher the level of IT outsourcing project, and the greater the degree of impact on customer. In this paper, using the method of Kevin, according to the degree of the impact of the strategy, we divide the project into three levels: High, Medium and Low, such as Table 2.

Table 2. IT outsourcing project level.

\begin{tabular}{|c|c|c|}
\hline $\begin{array}{c}\text { Project } \\
\text { level }\end{array}$ & $\begin{array}{c}\text { Impact } \\
\text { to strat- } \\
\text { egy }\end{array}$ & Main content \\
\hline Low & Low & $\begin{array}{r}\text { Equipment management, System } \\
\text { management }\end{array}$ \\
\hline Medium & Medium & $\begin{array}{c}\text { Business process, Value chain } \\
\text { integration }\end{array}$ \\
\hline High & High & $\begin{array}{c}\text { Strategic development and sup- } \\
\text { port }\end{array}$ \\
\hline
\end{tabular}

\section{Analysis on the evolution process of IT outsourcing relationship}




\subsection{Analysis on the evolution process of IT outsourcing relationship quality}

The evolution of relationship quality is the development process of relationship quality from low to high. Arnold and Joshi believes that both vender and customer can establish a high relationship through the repeated flexibility, information exchange behavior and the positive cycle of solidarity, which is advantageous to reduce the opportunism tendency and promotes mutual trust [15].

In the book "beyond the partnership: innovation strategy and lean supply ", cording to the development process of things, Lamming divided enterprises relationship into five stages: (1) the traditional relationship stage; (2) free competition stage (3) cooperative relationship stage; (4) partnership stage; (5) strategic alliance stage. From above all, we can see that the relationship between enterprises is a continuous evolution process from market relationship, cooperative relationship to partnership. Thus, the evolution of the relationship between enterprises is a gradual process, the relationship between IT vendor and customer is no exception, and the evolution of relationship quality between the two sides is shown in Figure 1.

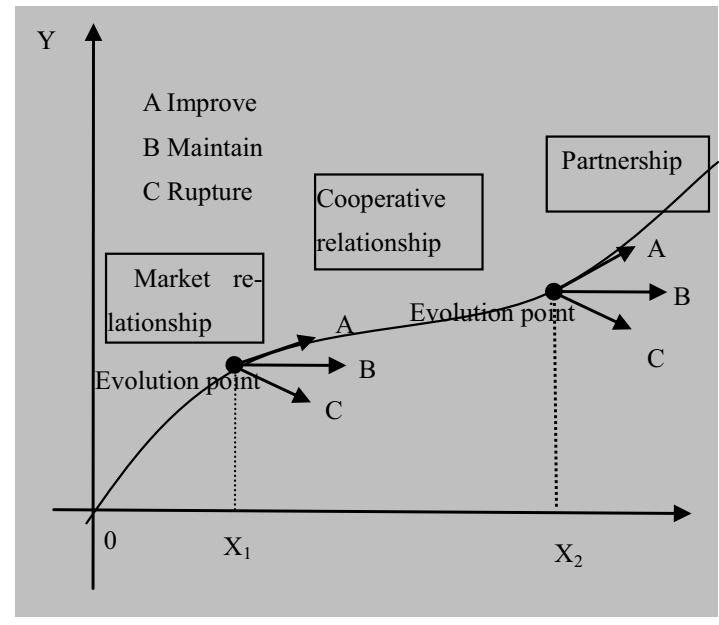

Fig.1. The evolution process model of outsourcing relationship quality.

In Figure 1, $\mathrm{X}$ indicates the Time, $\mathrm{Y}$ represents the evolution process of the IT outsourcing relationship quality. As X goes on, $\mathrm{Y}$ is a continuous evolution process. Based on the quantitative change, relationship quality has qualitative change in $\mathrm{X} 1$ and $\mathrm{X} 2, \mathrm{X} 1$ and $\mathrm{X} 2$ are called evolution points. After evolution points, the IT outsourcing relationship quality will be split in three directions:

(1)Evolutionary path A shows that the degree of trust between vender and customer achieves quantitative improvement and development by communication and cooperation.

(2)Evolutionary path B shows that vender and customer maintain their trust level by communication and cooperation.

(3)Evolutionary path $\mathrm{C}$ shows that the vender and customer find that the other side is not worthy of trust, trust is destroyed, the relationship ruptures.

\subsection{Analysis on the evolution process of IT outsourcing project}

IT customer investigates the IT vendor through the implementation process of each IT outsourcing project. In the start-up phase of implementation process of the IT outsourcing project, the IT customer pays attention to the service capability of IT vendor; in the implementation process of IT outsourcing project, the IT customer will track and evaluate the implementation of IT project, so as to further understand the comprehensive ability of the IT vendor; With the implementation of IT outsourcing project, the IT customer gradually learn and absorb the IT technology, management skills, IT knowledge and experience; At the end of implementation process of the IT outsourcing project, the IT 
customer will have a more comprehensive understanding and evaluation to the overall capacity of the IT vendor. In fact, with the need of strategic adjustment and process innovation, the IT customer will produce multiple needs of IT outsourcing. That is to say, the development of IT outsourcing project' level is a multi cycle and dynamic evolution process, as shown in Figure 2.

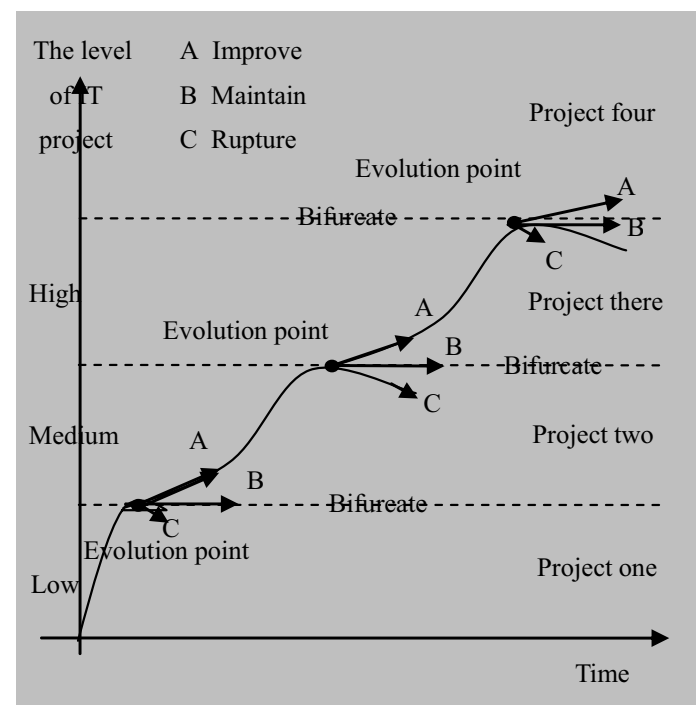

Fig.2. The evolution process model of IT outsourcing project level.

Implementation process of each IT outsourcing project is the process of IT customer to understand the IT vendor's ability. The completion point of this IT project may be the beginning of the next IT project, and this point is called evolution. After evolution points, the level of IT outsourcing project will be split in three directions:

(1)Evolutionary path A shows that the cooperation of this IT outsourcing project is very successful, the customer is very satisfied to service ability of the vender and will consider a higher level of IT outsourcing project, so that the level of IT outsourcing project gets improvement.

(2)Evolutionary path B shows that the cooperation of this IT outsourcing project is basically successful, the customer is basically satisfied to service ability of the vender, but the customer is not very sure that the service ability of higher level IT project, it will maintains the cooperation of this IT project and not consider other cooperation.

(3)Evolutionary path $\mathrm{C}$ shows that the customer is not satisfied to service ability of the vender, so it eliminates the vendor and results in a broken relationship.

\section{The evolution process model of IT outsourcing relationship}

IT outsourcing relationship is the relationship of two organizations between vendor and customer; its evolution process is bound to be influenced by various powers from internal and external environment of the organizations. IT outsourcing relationship is constantly evolving under the influence of the external and internal powers of the organizations. According to the principle of synergetic, when powers from the government, market, society and technology are enhanced, exchange trend of product and service and competitive position will be changed.

The IT customer feels the pressure of enterprise information and understands the potential value of using information technology to enhance the enterprise performance, thus resulting in a more intense need of IT outsourcing, so the IT customer will further strengthen cooperation with the IT vendor and further consider outsourcing the next higher level of IT outsourcing project. At the same time, the IT vendor feels the IT need of IT customer and knows customer's ability requirements of IT outsourcing service, and then continue to improve the relationship and the service ability of high-level IT outsourcing project. The synergy between the customer and vendor forms the internal driving 
force of the evolution of the IT outsourcing relationship. The IT customer, vendor and other subjects from environment mutually promotes the evolution of IT outsourcing relationship.

Under the pressures of external and internal powers, the IT outsourcing relationship is becoming more and more closely, and the level of IT outsourcing projects is higher and higher. Under the mutual pressures IT outsourcing relationship is evolved from junior to senior, from simple to complex.

In the whole system of IT outsourcing relationship, all subsystems are in a common environment, and each subsystem is in a small environment. IT outsourcing relationship is evolution adaptively in the small environment, and this adaptive capacity is a kind of intelligent expression. In the evolution process of IT outsourcing relationship, the subjects constantly adjust their own behaviors to adapt to the needs of the environment, and continue to accumulate experience to ensure that they do better next time. In turn, the behaviors of a large number of subjects of IT outsourcing relationship in the environment are constantly changing the environment; coupled with the change of environment itself, the dynamic environment affects subjects of IT outsourcing relationship as a form of "constraints". After repeated cycles, the subject and environment of IT outsourcing relationship are in a process that is long-term, mutual influence, mutual interaction, and mutual evolution.

In summary, the evolution of IT outsourcing relationship is a dynamic feedback process in which subjects to external environmental stimulation is from perception to response. The evolution of relationship quality and IT outsourcing project has certain periodicity. In the process of the IT outsourcing relationship evolution, the relationship quality is periodic development along Low - Medium - High degree of trust, the level of IT outsourcing projects is periodic development along Maintenance - Improve - Bifurcate - Maintain, as shown in Figure 3.

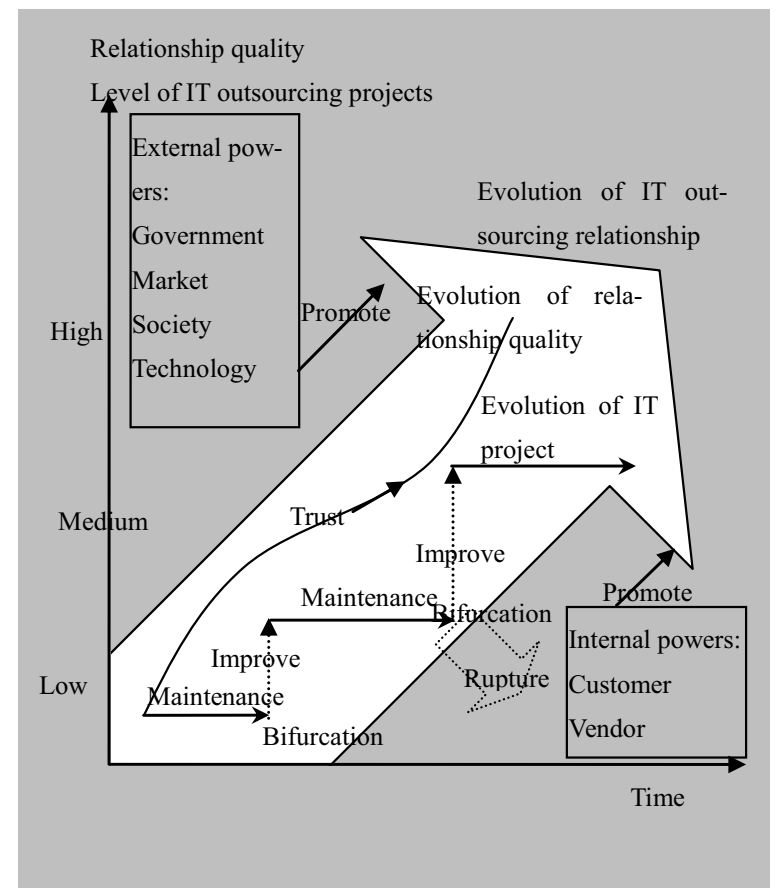

Fig.3. The evolution process model of IT outsourcing relationship.

\section{Conclusions}

In order to discuss how to manage the IT outsourcing relationship, this paper deeply analyzed the evolution process of IT outsourcing relationship. Firstly it analyzed the types of IT outsourcing based on relationship quality and IT outsourcing project level; Secondly two evolution process models of IT outsourcing relationship was proposed based on 
relationship quality and IT outsourcing project level, and they indicated the IT outsourcing relationship evolution process; Then an IT outsourcing relationship evolution process model was developed, and it explained the development process of IT outsourcing relationship from low to high under the internal and external power.

This research can help the IT customer to understand the evolution process of outsourcing relationship between IT customer and vender, so as to effectively guide the IT customer to manage the IT outsourcing relationship and improve the success rate of IT outsourcing.

\section{Acknowledgment}

This work was supported by the Social Science Foundation of Jilin province education office (Grant No. 2016068).

\section{References}

1. Xiaoyun Qi. An empirical study on the macro growth process of enterprise information system in China.Changchun: management college of Jilin university, 2008.

2. Kern T. The Gestalt of an Information Technology Outsourcing Relationship: An Exploratory Analysis. Atlanta Georgia 18thInternational Conference on Information Systems, 1997, December: 15-17.

3. Goles T. The Impact of the Client-Vendor Relationship on Information Systems Outsourcing Success. Bauer College of Business. Houston: University of Houston University Park, 2001.

4. Grover V, Cheon M J, Teng J T C. The Effect of Service Quality and Partnership on the Outsourcing of Information Systems Functions. Journal of Management Information Systems, 1996, 12(4):89-116.

5. Lee J N, Kim Y G. Effect of Partnership Quality on IS Outsourcing Success: Conceptual Framework and Empirical Validation. Journal of Management Information Systems. 1999, 15(4):29-61.

6. Qi C, Patrick Y K. Does interpersonal trust also matter? Exploring the role of trust in successful IT outsourcing. The Proceedings 0f the 40th Hawaii imitational conference on system sciences, 2007:1530-1605.

7. Ravald A, Grobnroo s C. The Value Concept and Relationship Marketing. European Journal of Marketing, 1996, 30 (2): 19-30.

8. Yi Qin. Study on IT outsourcing relationship quality. Journal of management, 2006, 3(6):669-672.

9. Alborz S, Scheepers R, Seddon P B. Impact of Configuration on IT Outsourcing Relationships. Paper presented at the Tenth Americas Conference on Information System, New York, 2004.

10. Nam K, Rajagopalan S, Rao H R, Chaudhury. A two-level investigation of information system outsourcing. Communications of ACM 7, 1996, 39(7):36-44.

11. Kern T, Willcocks L P. The Relationship Advantage: Information Technologies, Sourcing, and Management. Oxford: Oxford University Press, 2001.

12. Kevin J D. IT outsourcing relationships: An Exploratory Study of Inter-organizational Control Mechanisms. Cambridge: Harvard University Graduate School of Business Administration, 1996.

13. Anyi Tian. Study on the dynamic mechanism of enterprise information.Beijing: Chinese Academy of Social Sciences, 2008.

14. Jianbin Sun, Yingying Li. Comparative analysis of information technology outsourcing model. Commercial era, 2008(31):85-86.

15. Joshi A W, Amold S J. The Impact of Buyer Dependence on Buyer Opportunism in Buyer Supplier Relationships: The Moderating Role of Relational Norms. Psychology \& Marketing, 1997, 14(18):823-845. 